\title{
Biomass explains the intensity of facilitative - not competitive - interactions: three intraspecific tests with annuals
}

\author{
C. Ariza and K. Tielbörger \\ Department of Plant Ecology, University of Tübingen, Auf der Morgenstelle 3, 72076 Tübingen, Germany \\ Correspondence to: K. Tielbörger (katja.tielboerger@uni-tuebingen.de)
}

Received: 29 January 2012 - Revised: 20 August 2012 - Accepted: 29 August 2012 - Published: 1 October 2012

\begin{abstract}
Despite efforts to discern the role of plant size in resource competition, the circumstances under which size-dependent plant-plant interactions occur are still unclear. The traditional assumption is that competition intensifies with increasing neighbour size. However, recent studies suggest that the size (biomass) dependence of competitive interactions is strongest at very low biomass levels and becomes negligible after a certain threshold neighbour biomass has been reached. We searched for the generality of such patterns for three common annual plant species in Israel. We monitored target and neighbour biomass along their entire lifecycle using an even-aged, intraspecific and intrapopulation competition screenhouse experiment under water-limited conditions. For all focal species, neighbour presence had a net negative effect on vegetative biomass at harvest. However, this was not explained by increasing neighbour biomass over time, as a consistent pattern of sizedependent facilitative, rather than competitive, interactions was observed at all life stages. We explain these observations in terms of co-occurring aboveground facilitation and dominant belowground competition for water. Since our findings are the first of their kind and contradict theoretical predictions of biomass dependence of net negative interactions, we advocate further experiments addressing size dependence in interactions among plants. In particular, theoretical models addressing size dependence of positive interactions must be developed.
\end{abstract}

\section{Introduction}

The importance of competition for determining structure and function of plant populations and communities has long been recognized. Despite the vast number of experiments conducted to establish general rules for the outcome of interactions among plants, our understanding of the mechanisms through which plants compete for resources is still limited (Tilman, 1987, 2007; Schwinning and Weiner, 1998).

The role of plant size in resource competition has been approached from theoretical and experimental angles. Studies of competitive symmetry have shown that larger size may confer a disproportionate advantage for resource preemption (reviews in Weiner, 1990; Casper and Jackson, 1997; Schwinning and Weiner, 1998) which can affect the size distribution of individuals in crowded populations (e.g. Weiner, 1985; Weiner et al., 2001; but see Bonan, 1991). The benefits of larger size are also evident in studies of competitive ability (e.g. Grace, 1985; Gaudet and Keddy, 1988; Keddy et al., 2002), and are considered in most models of plant life history strategies (e.g. Grime, 1979; Tilman, 1982).

Common to these theories is the implicit assumption of a positive relationship between total plant biomass (size) and resource uptake (e.g. Goldberg, 1987). As a consequence, it has also been assumed that competition intensity is positively related to the size or biomass of the interacting individuals. Therefore, competition should intensify through time as plants grow and increase their resource uptake (i.e. from small seedlings to adults).

While changes in magnitude and direction of interactions among life history stages have been reported (e.g. Miriti, 2006; Schiffers and Tielbörger, 2006) and have sometimes been attributed to increasing biomass with age, there are virtually no studies that directly relate such changes to the size of all interacting individuals through time (but see Weigelt 
et al., 2002). Therefore, we still do not know whether or not biomass determines shifts in competition intensity through a plant's lifetime. Based on models of competition intensity, Weigelt et al. (2002) proposed that the biomass dependence of competitive interactions should be strongest at very low levels of neighbour biomass (i.e. early life-history stages) but weakens as allocation strategies gain importance with increasing yield and/or age. Other studies (Bonser and Reader, 1995; Hager, 2004; Navas and Moreau-Richard, 2005) suggest that biomass effects on competitive interactions become insignificant after the neighbour biomass reaches a certain threshold (at later life-history stages). Such a threshold yield could partly explain the inconsistent detection of sizedependent interactions in previous studies (i.e. Reader et al., 1994; Milbau et al., 2007 and references therein) as measures were mostly conducted within limited biomass ranges and at a single life stage. Unfortunately, very few studies have searched for the existence of the threshold neighbour biomass (Navas and Moreau-Richard, 2005) and only one (Weigelt et al., 2002) has evaluated ontogenic changes in the biomass dependence of competitive interactions. Thus, our understanding of why plant interactions change with time or with neighbour size is still limited.

Here, we present experimental evidence for such shifts from an experiment in which we monitored the relationship between neighbour biomass and competition intensity along the lifecycle of three annual plant species. We predicted that the strength of the relationship would decline with increasing yields/age (Weigelt et al., 2002) and drop sharply after a certain threshold neighbour biomass has been reached.

\section{Materials and methods}

We tested our prediction using an even-aged intraspecific and intrapopulation, target-neighbour competition design under homogeneous conditions in a screenhouse, i.e. an openair setting protected from animals by nettings. For the sake of generalization, we used species from different functional groups with different germination behaviour. In this study, different ranges of neighbour biomass per species were not sought by including different density treatments, but by studying individuals from a range of climatically different populations which naturally differ in size, over their lifecycles - increasing the likelihood of having a larger range of sizes included in the experiment. At the same time, the use of an intrapopulation setup permitted us to largely control for size advantages (priority effects through early germination) and variation in competitive ability among interacting individuals. Additionally, it allowed non-destructive estimates of neighbour biomass at different life stages and avoided the confounding of density with neighbour identity that occurs in interspecific experiments.

\subsection{Plant material}

Three winter annual species in Israel were used in this experiment: the crucifer Biscutella didyma L., the legume Hymenocarpos circinnatus (L.) Savi, and the grass Stipa capensis Thunb. These species were selected because they are common and differ largely in size, germination behaviour and thus potentially in competitive ability.

We randomly collected seeds at the end of spring 2004, at four research stations established along a south-north rainfall gradient in Israel. Separated by approximately $200 \mathrm{~mm}$ of average rainfall, the collection sites represent arid (A) semiarid (SA), Mediterranean (M) and mesic Mediterranean (MM) zones (Petrů et al., 2006). They are located over the same calcareous bedrock on south-facing slopes and experience similar average temperatures.

The distribution of the species along the gradient allowed collecting seeds from $B$. didyma at all four stations, from $H$. circinnatus at the three wetter sites and from $S$. capensis at the three drier sites. From previous studies we know that annual plant populations along the gradient differ in morphological and phenological traits as well as in competitive response ability (Petrů et al., 2006; Schiffers and Tielbörger, 2006; Liancourt and Tielbörger, 2009). To ensure natural breaking of summer dormancy, collected seeds were placed in bags of transparent, permeable synthetic fabric and attached to the ground surface at their respective sites of origin (as in Liancourt and Tielbörger, 2009). The bags were removed from the field in October 2004.

\subsection{Screenhouse experiment}

Seeds were planted in November 2004 in pots filled with a mixture of loess soil and sand $(2: 1)$. Loess mimicked field conditions; sand was added for decreasing excessive drought stress due to evaporation. A handful of Osmocote Scott ${ }^{\circledR}$ fertilizer was added per 151 soil mixture. Pots measuring $12 \mathrm{~cm}$ diameter $\times 12 \mathrm{~cm}$ depth were used for $B$. didyma and $S$. capensis. Due to its prostrate nature, $18 \mathrm{~cm}$ diameter $\times 18 \mathrm{~cm}$ depth pots were used for $H$. circinnatus.

Our experiment consisted of ten replicates per population of paired target plants, with one target from the pair growing in a pot in isolation (control) and the other in a pot with neighbours of its own population (competition). In total, 200 pots were used ( 80 for $B$. didyma: 4 populations $\times 2$ neighbour treatments $\times 10$ replicates; 60 for each of the other two species: 3 populations $\times 2$ neighbour treatments $\times 10$ replicates). To ensure sufficient germination, 10 diaspores were placed in control pots and approximately 40 in pots of the competition treatment, 10 of which were used for target generation. All pots experienced identical light and water regimes at a screenhouse of the Hebrew University of Jerusalem, in Rehovot, Israel. Plants were manually irrigated twice per week in winter and more often in late spring, always ensuring the same amount of water was applied to all 
pots (irrigation was conducted slowly and only stopped when water started dripping from the pots). The location of paired pots was randomized three times during the experiment.

Germination was closely monitored after the first irrigation (1 December 2004). The earliest germinating seedling in the centre of the pot was designated as target and marked with a colourful thread. To ensure similar size of neighbours and targets, the earliest germinating plants were selected as neighbours. After emergence of one target in control pots and one target plus seven neighbours in competition pots, all new seedlings were removed. We followed germination and growth three times per week during the first month of the experiment and approximately twice per week thereafter, until 12 April 2005, when the last plants were harvested. Survival, height, number of leaves and reproductive status were recorded for the target individuals at each visit. The number of surviving neighbours was registered in 23 of the 36 visits performed.

Each target plant was harvested at its individual seed set; thus paired targets were not necessarily collected on the same date. After harvesting and drying at $70^{\circ} \mathrm{C}$ for $48 \mathrm{~h}$, we recorded the number of leaves and diaspores and the total aboveground plant biomass. Neighbours in competition pots were harvested along with their respective targets, dried and weighed.

\subsection{Data analysis}

Total aboveground dry biomass was used as surrogate for target size. We used leaf number as a non-destructive measure for aboveground biomass, because it is highly correlated with biomass (Schiffers and Tielbörger, 2006). We confirmed this and, hence, equations obtained from significant quadratic regressions with intercept zero were used for the estimation of target biomass at each measuring date.

For the calculation of competition intensity, we also estimated the total biomass of neighbours, only for dates at which they were counted. We assumed that all individuals in a pot had similar size and biomass as the target and obtained the biomass of neighbours by multiplying the estimated biomass of the target plant by the number of neighbours present. Although assuming symmetry in the size distribution of neighbours may be rough, during most of the experiment the formation of size hierarchies due to competition for light was avoided in this naturally well-illuminated setting by using a low density and even-aged plants from the same populations. No major differences in the size of competing individuals within pots were observed during 23 dates at which neighbours were counted. Given the low frequency of irrigation provided to all plants, belowground competition for water was expected to occur, and was expected to be sizeindependent if target and neighbours did not differ in average size. Finally, linear regression analyses conducted for each species and population, with individual target biomass at harvest as independent variable and average individual neigh- bour biomass at harvest as dependent variable, confirmed our assumption: all significant regressions had a positive slope that did not differ significantly from one and an intercept that did not differ from zero. Our assumption was further tested through correlation analyses between the recorded total dry biomass of neighbours at harvest and the estimated total biomass of neighbours calculated from the target biomass multiplied by the neighbour number at harvest. The correlation was strong (B. didyma $R=0.7 ; S$. capensis $R=0.7 ; H$. circinnatus $R=0.6)$ and highly significant $(P<0.001)$ for all species.

For each pair of targets, competition intensity was calculated at each age (measured as days after germination), using the relative interaction index (Armas et al., 2004), RII. $\mathrm{RII}=\left(\mathrm{P}_{+\mathrm{N}}-\mathrm{P}_{-\mathrm{N}}\right) /\left(\mathrm{P}_{+\mathrm{N}}+\mathrm{P}_{-\mathrm{N}}\right)$, where $\mathrm{P}_{+\mathrm{N}}$ represents target performance in the presence of neighbours and $\mathrm{P}_{-\mathrm{N}}$ performance in isolation. RII ranges between -1 and +1 , with negative values denoting competition and positive values defining facilitative interactions.

To evaluate whether competition indeed occurred, we first analyzed the effect of population origin and neighbour presence on target biomass at harvest using a repeated-measures ANOVA, with neighbour presence as the within-subject factor.

The relationship between competition intensity and growth of interacting individuals was evaluated for each species, through a sequence of linear regressions with RII as dependent variable and estimated dry biomass of neighbours as the independent variable. For each species, four regressions were performed, one for each three-week age range. For $H$. circinnatus and $S$. capensis, both with a longer lifespan than B. didyma, the last regression included a four-week plant development period. As neighbour biomass averages did not strongly differ between populations for any of the studied species, all regressions were performed on pooled population data. We chose this age range regression approach aware of lack of independence among several data points, as regressions by weekly age intervals suffered from similar data interdependency in addition to small sample sizes and very low power, which constrained the generalization of results.

To accept our hypothesis, we expected a significantly negative relationship between total neighbour and target biomass on the regressions performed with data from early life stages but weaker, non-significant relationships between total neighbour and target biomass at later life stages, when larger neighbour biomass was included in the regressions (i.e. biomass has smaller explanatory power). Note that the data used in these regressions correspond to measures conducted on targets of similar age and were not necessarily collected on the same date.

STATISTICA (version 7 for Windows, StatSoft, 2004) was used for all analyses. 
Table 1. Results of repeated-measures ANOVAs testing the effect of population origin and neighbour presence on aboveground biomass at harvest of targets of Biscutella didyma, Stipa capensis and Hymenocarpos circinnatus. $* * P<0.01, * * * P<0.001$.

\begin{tabular}{|c|c|c|c|c|c|c|c|c|c|}
\hline \multirow[b]{2}{*}{ Source of variation } & \multicolumn{3}{|c|}{ B. didyma } & \multicolumn{3}{|c|}{ S. capensis } & \multicolumn{3}{|c|}{ H. circinnatus } \\
\hline & $\mathrm{df}$ & $F$ & $P$ & df & $F$ & $P$ & $\mathrm{df}$ & $F$ & $P$ \\
\hline Population & 3 & 1.770 & ns & 2 & 0.680 & ns & 2 & 2.429 & ns \\
\hline Neighbours & 1 & 14.348 & $* * *$ & 1 & 17.719 & $* * *$ & 1 & 11.376 & $* *$ \\
\hline Neighbours $\times$ Population & 3 & 1.177 & ns & 2 & 0.094 & ns & 2 & 2.485 & $\mathrm{~ns}$ \\
\hline
\end{tabular}

\section{Results}

\subsection{Effect of neighbours on target biomass at harvest}

The results of the repeated-measures ANOVAs on target biomass at harvest showed for all species significant negative neighbour effects and no differences among target populations (Table 1). On average, neighbour presence reduced the final biomass of target individuals of B. didyma, S. capensis and $H$. circinnatus by $25 \%, 30 \%$ and $37 \%$, respectively.

\subsection{Progression of biomass effects on the intensity of plant-plant interactions}

The intensity of plant interactions did not progress with biomass as predicted, because, for all species, RII and neighbour biomass were not negatively but positively related at all age ranges (Table 2, Fig. 1), indicating that targets that were less suppressed by competition were found in pots with greater neighbour biomass. The neighbour biomass ranges at which significant correlations were detected varied among species; the relationship between RII and neighbour biomass was always significant in $S$. capensis, significant from the third week of life until the last age period analyzed in $H$. circinnatus and, only in $B$. didyma, the relationship followed the predicted pattern of high significance from the earliest stages and weakening later on, at the last period of plant development measured. Interestingly, for all species, the slope of the regression line consistently levelled off with inclusion of later age ranges (Fig. 1).

\section{Discussion}

Our results show a striking and consistent positive correlation between neighbour biomass and RII for all species and at most life stages, indicating biomass-dependent facilitation rather than competition.

Weigelt et al. (2002) proposed that the relationship between competition intensity and neighbour biomass follows a positive hyperbolic function, with high dependence of competition on biomass at low neighbour biomass (or early lifehistory stages). At a first glance, our results for B. didyma agree with their model. However, Weigelt et al. (2002) described only biomass-dependent competitive interactions, i.e.
Table 2. Coefficient of determination values for linear regressions of plant interaction intensity (RII - Relative Interaction Index) on neighbour biomass at different age ranges. Interaction intensity was calculated on pooled population data for Biscutella didyma, Stipa capensis and Hymenocarpos circinnatus. The signs of the correlations are shown next to each $R^{2}$ value. Sample size and maximum neighbour biomass at each age range are also presented. $* P<0.05$, $* * P<0.01, * * * P<0.001$.

\begin{tabular}{|c|c|c|c|c|}
\hline \multicolumn{5}{|c|}{ B. didyma } \\
\hline Age range & $R^{2}$ & & $N$ & $\begin{array}{c}\text { Maximum Neighbour } \\
\text { Biomass (g) }\end{array}$ \\
\hline $0-3$ weeks & $0.144 * * *$ & $(+)$ & 89 & 0.26 \\
\hline 4-6 weeks & $0.363 * * *$ & $(+)$ & 104 & 0.62 \\
\hline 7-9 weeks & $0.305 * * *$ & $(+)$ & 73 & 0.81 \\
\hline 10-12 weeks & 0.04 & $(+)$ & 50 & 2.30 \\
\hline \multicolumn{5}{|c|}{ H. circinnatus } \\
\hline Age range & $R^{2}$ & & $N$ & $\begin{array}{c}\text { Maximum Neighbour } \\
\text { Biomass (g) }\end{array}$ \\
\hline 0-3 weeks & 0.026 & $(+)$ & 43 & 0.18 \\
\hline 4-6 weeks & $0.114 * *$ & $(+)$ & 66 & 0.72 \\
\hline 7-9 weeks & $0.095^{*}$ & $(+)$ & 51 & 2.86 \\
\hline 10-13 weeks & $0.210 * *$ & $(+)$ & 42 & 14.80 \\
\hline \multicolumn{5}{|c|}{ S. capensis } \\
\hline Age range & $R^{2}$ & & $N$ & $\begin{array}{c}\text { Maximum Neighbour } \\
\text { Biomass (g) }\end{array}$ \\
\hline $0-3$ weeks & $0.085 * *$ & $(+)$ & 78 & 0.16 \\
\hline 4-6 weeks & $0.215^{* * * *}$ & $(+)$ & 72 & 0.54 \\
\hline 7-9 weeks & $0.446 * * *$ & $(+)$ & 39 & 0.70 \\
\hline $10-13$ weeks & $0.339 * * *$ & $(+)$ & 28 & 1.45 \\
\hline
\end{tabular}

they assumed that RII and biomass should be negatively related. Surprisingly, our separate regressions show a completely consistent pattern of positive, rather than negative, correlations throughout the entire life span of the plants. This makes a strong point against our initial hypothesis and the idea that biomass explains a large proportion of competition intensity at low biomass levels (Weigelt et al., 2002).

Remarkably, while neighbour biomass was positively related to the intensity of interactions at all life stages, neighbour presence had a net negative effect on target biomass at harvest for all species. We interpret these findings as 

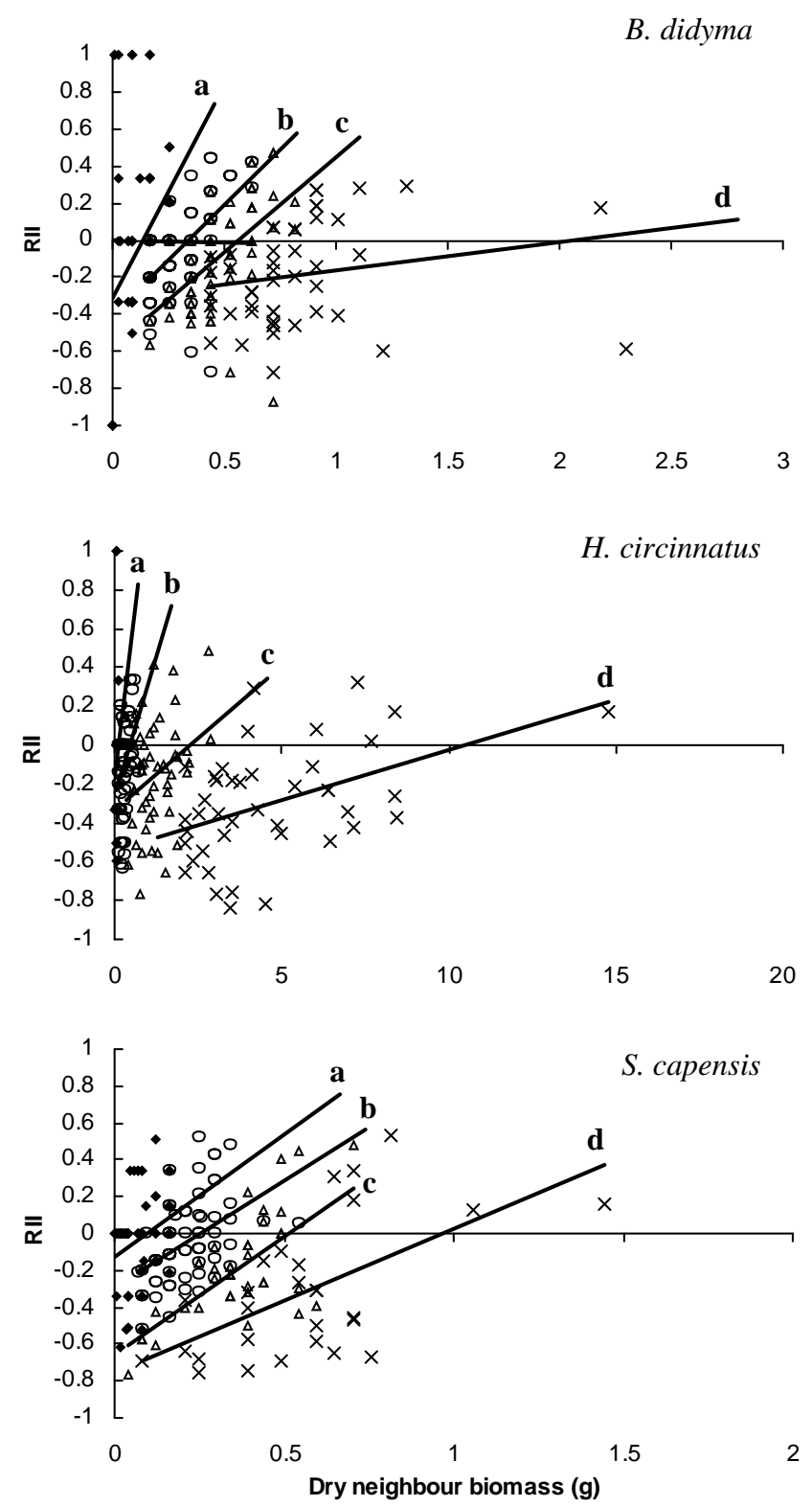

Figure 1. Relationship between interaction intensity (measured as RII) and neighbour biomass for pooled populations of Biscutella didyma, Stipa capensis and Hymenocarpos circinnatus. For all species, separate linear regression lines are presented for data collected between 0-3 weeks of age (filled diamonds, line a), 4-6 weeks (open circles, line b), 7-9 weeks (open triangles, line c) and 10-13 weeks (x marks, line d), except for B. didyma where (d) was calculated for the 10-12 weeks age range.

evidence for the co-occurrence of facilitation and competition during the course of the life history of plants in this study. Under water-limiting and high light conditions, such as those in our experiment, one may assume that belowground interactions are predominantly negative (competition for water), while aboveground neighbour effects on water availability are predominantly positive, due to reduced soil evapotranspiration and radiation provided by neighbours' shade. Biomass-dependent net positive interactions should then be observed during growth if the shading effect increases with increasing leaf area of growing neighbours. The positive effect weakened and turned neutral during the last three weeks of life of $B$. didyma. This could be considered an indication of a threshold neighbour biomass constraining size-dependent positive interactions, and is intriguing because such a threshold has been proposed previously (Hager, 2004; Navas and Moreau-Richard, 2005) in studies that focused on competition, not facilitation. However, in our study, age-dependent interactions in B. didyma became neutral during the period of seed set and thus the change could be related to the physiological changes brought on by reproduction, when resources are invested in reproductive organs at the expense of vegetative growth, as is typical in annuals (Bazzaz et al., 1987) compared to a simple threshold biomass. It must be noted that biomass and age (e.g. developmental stage) are necessarily confounded in our setup. We believe however that neighbour biomass is a good predictor of target performance in this study, because the interactions explained by biomass were always facilitative; the analyses were based on, to our knowledge, the closest monitoring of biomass changes through time for annuals and because it has been suggested before that plant size is the main determinant of plant interactions.

A simple qualitative inspection of our weekly data indicates that a similar process could have occurred in $H$. circinnatus and $S$. capensis after the 13th week of growth. However, very small sample sizes after this age did not allow us to include an extra age class. While survival to reproduction was over $70 \%$ for all focal species, the small sample sizes were mostly due to the harvesting of most targets without neighbours by their 14th week of age, as these flowered and set seeds on average a week earlier than those grown with competitors.

Unfortunately, there are no theoretical predictions on the biomass dependence of facilitative interactions. Though some previous studies support our conclusions, there are only a few studies that may help us to interpret our findings. This is partly due to the fact that most facilitation literature focuses on interactions between different life forms, such as the nurse plant effect between shrubs and annuals (e.g. Holzapfel et al., 2006; Li et al., 2010) and few studies have looked at facilitative interactions within a life form or even species (e.g. Schiffers and Tielbörger, 2006; Leger and Espeland, 2010). Some support for our interpretation about the facilitative mechanism can be found in studies observing lower temperatures and decreased evaporation from the soil surface due to herbaceous plant cover (e.g. Rietkerk, 1998; Maestre et al., 2001). Yet, our study is the first to suggest such an effect under controlled experimental conditions.

The observed facilitative effect of neighbour biomass on interaction intensity is probably not unique, though no theoretical model has yet addressed it. Interestingly, similar 
results have previously been reported but overlooked, probably because of the focus on competitive rather than facilitative interactions. One example is the study of Weigelt et al. (2002), who claimed lack of correlation between neighbour biomass and interaction intensity in an experiment conducted with adult plants. Yet, there was a significant decline in the strength of competition with increasing neighbour biomass in two of their nine competition treatments. Similarly, Milbau et al. (2007) found significant facilitative effects of neighbour biomass on target performance for one of four target species in a field pot experiment. It is possible that positive neighbour biomass effects are common in competition experiments, but pass unnoticed, if neutral or net negative neighbour effects are detected or if, as in most plantplant interaction studies (but see Brooker et al., 2008), the a priori focus of the study is on competition. Another factor may be that, for simplicity, experiments of plant-plant interactions usually use only two neighbour treatments (i.e. with vs. without neighbours) rather than manipulating neighbour abundance or biomass (see Weigelt and Jolliffe, 2003).

Although size dependence of plant-plant interactions is species-specific and may vary with resource levels and environmental conditions (Navas and Moreau-Richard, 2005), it may as well change along the lifecycles of interacting plants, as our research shows. Given the large theoretical implications of size dependence, it is important to discern the rules that govern this process. This will not only require further recording of short-term dynamics and ontogenic aspects of plant-plant interactions but also developing novel models that include facilitative effects.

Acknowledgements. We thank J. Kigel and M. Sternberg for logistic support, Peter Stoll for helpful discussions and T. Acuña, O. Ebinger, E. Farfan, S. Khadka, H. Mageed, M. Niño, H. Rueff, Y. Rutten, A. Tzabari and L. Yakir for assisting in field and labwork. This study is part of the GLOWA Jordan River project, funded by the German Federal Ministry of Education and Research (BMBF).

Edited by: H. Heilmeier

Reviewed by: three anonymous referees

\section{References}

Armas, C., Ordiales, R., and Pugnaire, F. I.: Measuring plant interactions: a new comparative index, Ecology, 85, 2682-2686, 2004.

Bazzaz, F. A., Chiariello, N. R., Coley, P. D., and Pitelka, L. F.: Allocating resources to reproduction and defense, BioScience, 37, 58-67, 1987.

Bonan, G. B.: Density effects on the size structure of annual plant populations: an indication of neighbourhood competition, Ann. Bot., 68, 341-347, 1991.

Bonser, S. P. and Reader, R. J.: Plant competition and herbivory in relation to vegetation biomass, Ecology, 76, 2176-2183, 1995.
Brooker, R. E., Maestre, F. T., Callaway, R. M., Lortie, C. L., Cavieres, L., Kunstler, G., Liancourt, P., Tielbörger, K., Travis, J. M., Anthelme, F., Armas, C., Coll, L., Corcket, E., Delzon, S., Forey, E., Kikvidze, Z., Pugnaire, F., Saccone, P., Schiffers, K., Seifan, M., Touzard, B., and Michalet, R.: Facilitation in plant communities: the past, the present and the future, J. Ecol., 96, 18-34, 2008.

Casper, B. B. and Jackson, R. B.: Plant competition underground, Annu. Rev. Ecol. Syst., 28, 545-70, 1997.

Gaudet, C. L. and Keddy, P. A.: A comparative approach to predicting competitive ability from plant traits, Nature, 334, 242-243, 1988.

Goldberg, D. E.: Neighbourhood competition in an old-field plant community, Ecology, 68, 1211-1223, 1987.

Grace, J. B.: Juveniles vs. adult competitive abilities in plants: sizedependence in Cattails (Typha), Ecology, 66, 1630-1638, 1985.

Grime, J. P.: Plant strategies and vegetation processes, John Wiley \& Sons Ltd., Chichester, 1979.

Hager, H. A.: Competitive effect versus competitive response of invasive and native wetland plant species, Oecologia, 139, 140149, 2004.

Holzapfel, K., Tielborger, K., Parag, H. A., Kigel, J., and Sternberg, M.: Annual plant-shrub interactions along an aridity gradient, Basic Appl. Ecol., 7, 268-279, 2006.

Keddy, P., Nielsen, K., Weiher, E., and Lawson, R.: Relative competitive performance of 63 species of terrestrial herbaceous plants, J. Veg. Sci., 13, 5-16, 2002.

Leger, E. A. and Espeland, E. K.: The shifting balance of facilitation and competition affects the outcome of intra- and interspecific interactions over the life history of California grassland annuals, Plant Ecol., 208, 333-345, 2010.

Li, J., Zhao, C. Y., Song, Y. J., Sheng, Y., and Zhu, H.: Spatial patterns of desert annuals in relation to shrub effects on soil moisture, J. Veg. Sci., 21, 221-232, 2010.

Liancourt, P. and Tielbörger, K.: Competition and a short growing season lead to ecotypic differentiation at the two extremes of the ecological range, Funct. Ecol., 23, 397-404, 2009.

Maestre, F. T., Bautista, S., Cortina, J., and Bellot, J.: Potential for using facilitation by grasses to establish shrubs on a semiarid degraded steppe, Ecol. Appl., 11, 1641-1655, 2001.

Milbau, A., Reheul, D., de Cauwer, B., and Nijs, I.: Factors determining plant-neighbour interactions on different spatial scales in young species-rich grassland communities, Ecol. Res., 22, 242247, 2007.

Miriti, M. N.: Ontogenetic shift from facilitation to competition in a desert shrub, J. Ecol., 94, 973-979, 2006.

Navas, M.-L. and Moreau-Richard, J.: Can traits predict the competitive response of herbaceous Mediterranean species?, Acta Oecol., 27, 107-114, 2005.

Petrů, M., Tielbörger, K., Belkin, R., Sternberg, M., and Jeltsch, F.: Life history variation in an annual plant under two opposing environmental constraints along an aridity gradient, Ecography, 29, 66-74, 2006.

Reader, R. J., Wilson, S. D., Belcher, J. W., Wisheu, I., Keddy, P. A., Tilman, D., Morris, E. C., Grace, J. B., McGraw, J. B., Olff, H., Turkington, R., Klein, E., Leung, Y., Shipley, B., van Hulst, R., Johansson, M. E., Nilsson, C., Gurevitch, J., Grigulis, K., and Beisner, B. E.: Plant competition in relation to neighbour biomass: an intercontinental study with Poa pratensis, Ecology, 
75, 1753-1760, 1994.

Rietkerk, M.: Catastrophic vegetation dynamics and soil degradation in semi-arid grazing systems, Doctoral Dissertation, Wageningen University, Wageningen, 1998.

Schiffers, K. and Tielbörger, K.: Ontogenetic shifts in interactions among annual plants, J. Ecol., 94, 336-341, 2006.

Schwinning, S. and Weiner, J.: Mechanisms determining the degree of size-asymmetry in competition among plants, Oecologia, 113, 447-455, 1998.

Tilman, D.: Resource competition and community structure, Princeton Univ. Press, Princeton N.J., 1982.

Tilman, D.: The importance of the mechanisms of interspecific competition. Am. Nat., 129, 769-774, 1987.

Tilman, D.: Resource competition and plant traits: a response to Craine et al. 2005, J. Ecol., 95, 231-234, 2007.
Weigelt, A. and Jolliffe, P.: Indices of plant competition, J. Ecol., 91, 707-720, 2003.

Weigelt, A., Steinlein, T., and Beyschlag, W.: Does plant competition intensity rather depend on biomass or on species identity?, Basic Appl. Ecol., 3, 85-94, 2002.

Weiner, J.: Size hierarchies in experimental populations of annual plants, Ecology, 66, 743-752, 1985.

Weiner, J.: Asymmetric competition in plant populations, Trends Ecol. Evol., 5, 360-364, 1990.

Weiner, J., Stoll, P., Muller-Landau, H., and Jasentuliyana, A.: The effects of density, spatial pattern, and competititve symmetry on size variation in simulated plant populations, Am. Nat., 158, 438-450, 2001. 